\title{
INFORMAR SOBRE LA SEGURIDAD VIAL: REFLEXIONES MULTIDISCIPLINARES
}

Juan Tomás Frutos1: Universidad de Murcia. España jtomas@um.es

\section{RESUMEN}

La educación y el respeto, bases de la seguridad vial. Tiene el lector en sus manos una serie de consideraciones y de reflexiones de tono comunicativo-filosóficas en torno a los siniestros que se producen en el ámbito de la seguridad vial, que es, cuando menos, una denominación que llama a la perplejidad cuando uno hace balance de los accidentes de circulación que tienen lugar todos los años, que casi se asemejan, en ocasiones, a los datos de una guerra constante e inevitable. La educación, el ponderar los datos, el considerar que el respeto es básico para una normal convivencia humana son referentes en los que vamos a insistir en este capítulo, en el que vamos a subrayar la necesidad de potenciar la mentalización para no aceptar como un mal colmado de impotencia todo lo que se relaciona con el tráfico. La prudencia, la calma y el movernos con un margen de seguridad son notas básicas para evitar algunos episodios significados de heridos, de muertos, de dolor, de soledades, de familias rotas, de fragmentaciones de la realidad y de su decurso. El constante aprendizaje y el tener en cuenta a los demás son dos baluartes para reducir los accidentes y paliar sus fatales consecuencias.

PALABRAS CLAVE: Educación - Respeto - Informar - Seguridad vial - Reflexiones periodísticas

\footnotetext{
${ }^{1}$ Autor correspondiente

Juan Tomás Frutos: Profesor de la Universidad de Murcia. Decano del Colegio de Periodistas de la Región de Murcia (España).

Correo: jtomas@um.es
} 


\title{
KEIUKI ADUU I IUAN SECURITY: MULTIDISCIPLINARY REFLECTIONS
}

\begin{abstract}
The Education and the Respect, bases of the road security. The reader has in his hands a series of considerations and of communicative - philosophical reflections of a significative tone concerning the disasters that are produced in the field of the road security, which is a denomination that calls to the perplexity when one does a balance of the traffic accidents that take place every year, which almost they make alike, in occasions, to the information of a constant and inevitable war. The education, to weight the information, to think that the respect is basic for a normal human conviviality are relating in what we are going to insist on this chapter, in which we are going to underline the need to promote the indoctrination not to accept as an evil fulfilled with impotence everything that relates to the traffic. The prudence, the calmness and to move with a safety margin are basic notes to avoid some important episodes of injured men, of dead men, of pain, of lonelinesses, of broken families, of fragmentations of the reality and of its course. The constant learning and to have in count the others are two bastions to reduce the accidents and to relieve their fatal consequences.
\end{abstract}

KEY WORDS: Education - Respect - Report - Road security - Journalistic reflections

\section{INTRODUCCIÓN}

\subsection{Informar con la visión del ciudadano}

Me decido a referir algunas reflexiones sobre la presencia en los medios de comunicación de las víctimas de los accidentes de tráfico, de la conducción, de la circulación por las carreteras; y lo hago de mil amores en la convicción de que me mueve la buena voluntad y los mejores anhelos.

No obstante, soy consciente de que todos, y yo el primero, necesitamos unas culturas societarias de convivencia, de relación, en todos los ámbitos (por supuesto, en el de la educación vial también), que hasta ahora nos hacen deudores de una formación importante, $\mathrm{y}$, por lo tanto, reconozco que nos hallamos con señeras carencias de apoyo en la actualidad que nos deben impulsar a ir mejorando.

Además, subrayamos todo ello teniendo presente que lo más importante en cualquier acto de la vida cotidiana, que, en definitiva, en un acto de comunicación (el tráfico lo es), es que pensemos en los otros, en los demás, que no seamos endogámicos, que no rivalicemos, sino que procuremos aprender desde la apuesta decidida de desarrollarnos en sociedad, esto es, como parte de esa ciudadanía a la 
que nos debemos y por la que debemos laborar con firmeza.

Fruto de horas de estudio y de reflexión son los siguientes capítulos, breves ellos, prestos a arrojar un poco de luz sobre estos eventos complejos, complicados, no tanto por el hecho de que se trata de vidas humanas (que es muy relevante), sino por la alta dosis de sensibilidad que les acompañan. Esperamos no defraudar.

\section{DESARROLLO}

\subsection{Puntos básicos del proceso comunicativo}

El presente capítulo habla de comunicación en general, pero seguro que nos sirve como planteamiento básico a la hora de trazar un proceso comunicativo como éste, máximo en cuestiones de tráfico y de sus, a veces, nefastas consecuencias en forma de accidentes de diversa factura. El equilibrio entre emociones y raciocinio ha de ser el eje motor.

Busco sinónimos de comunicación, y me planto en ese escenario donde todo se configura como ausencia, puede que como la misma nada. No dejemos que las verdades absolutas, difíciles de hallar, si se encuentran en alguna parte, nos hagan confabularnos con un destino hostil e inquieto. No caigamos en las garras de ese porvenir que nos divide. La comunicación es todo lo contrario.

Nos hemos de convencer de que los flujos de ideas, de atenciones, de intereses, de cuestiones novedosas o interesantes, de lo que nos conviene y de lo que no... han de servir a los fines de todos y cada uno de los que intervienen en el proceso comunicativo. Y si no sirven, han de hacerlo. Hemos de buscar la pro-actividad, la movilización, para que todos nos entendamos y atendamos lo que acontece por un mundo más sencillo que complicado (aunque parezca al revés).

Entre las definiciones aparece la de cesión, esto es, nos hemos de convocar pensando en el otro, que ha de comprender que estamos en esa acción comunicativa por él, dispuestos a entenderle y a que nos entienda. No siempre hemos de tener razón. El otro debe saber que lo estimamos, que tenemos presentes sus historias, sus pasiones, lo que ha aprendido, lo que le desconcierta también.

Comunicación es, igualmente, escuchar. El rey Salomón deseó “un corazón a la escucha", un saber entender lo que siente y padece el otro. Las verdades no son ni tajantes ni eternas. Cada cual tiene la suya, en la interpretación machadiana. Cuando comunicamos hemos de tener en cuenta que esto es así. Los planteamientos de partida han de resumirse en el anhelo de aprender, pero todos de todos. No hay una certeza en una parte determinada. La hay en cualquier sitio donde tengamos la intención de hallarla. 
Asimismo, la comunicación tiene que ver con la empatía, con ese ponernos en el lugar del otro, con el entendimiento de sus circunstancias, de lo que piensa, de lo que ha padecido, abordando las cuestiones y los eventos que nos rodean desde su perspectiva, y no únicamente la nuestra. No nos dejemos impresionar por valores superficiales que lo que hacen es apartarnos del deseo de mirar al otro a la cara, a su rostro, a sus ojos (lo que más comunican) para comprender verdaderamente lo que nos dice y cómo nos lo hace saber.

Sin el contexto, buenos amigos míos (y amigas), no hay comunicación. Ésta se entiende en función de los condicionantes internos, externos, superficiales, íntimos, conocidos o no, que envuelven el proceso comunicativo. Por eso debemos contemplar ese paisanaje que decían los del 98 para acercarnos a la voluntad del otro (otro concepto de aquellos magníficos escritores). Pensemos que la voluntad, en cualquiera de sus gamas, también sustenta la comunicación, la buena comunicación. Si la hay, se producirá. De lo contrario confiaremos excepcionalmente en el azar. Conseguir la cercanía

Un concepto ya enunciado es la cercanía. Lo que más comunica es lo más cercano. Por eso hemos de procurar que se produzca esa proximidad. Entendemos más a los que se nos acercan en un espacio o tiempo, con circunstancias similares, con un lenguaje parecido (próximo), con intereses compartidos, con referencias asumibles y entendibles, etc. Pongamos como ejemplo de lo bien que funciona la cercanía a esos programas basados en una supuesta realidad, que se nos aproximan a través de lo que hace que todos los seres humanos del planeta nos entendamos, esto es, los sentimientos.

Lo malo es que esos espacios explotan de una mala manera esa proximidad, que adquiere, a menudo, tintes deplorables. No obstante, no lo olvidemos, la base comunicativa tiene su exponente en que el ser humano se entiende, de modo primario, mediante los sentimientos. Apelemos, aunque no nos hagan caso, a un buen uso de ellos.

Podríamos apelar, para terminar, a esos elementos siempre inconfundibles que conforman el proceso comunicativo, es decir, el emisor, el receptor, el mensaje, el código, el canal, y el contexto, sin olvidar la necesaria retroalimentación y esa importancia del lenguaje no verbal o gestual y de las distancias (cada una nos ofrece una información determinada), pero lo más relevante de todo es que pensemos que dos más dos no son cuatro en comunicación. Hay un intercambio de afectos, como ya se ha dicho, y de subjetividades (somos sujetos), que no podemos ponderar en todos los casos. Por eso quizá somos capaces de mostrarnos tan maravillosos (o no) en la comunicación.

Hagamos el esfuerzo en confiar (que también es una definición de lo que nos ocupa en este artículo), y así daremos con esa clave tan estupenda que nos dice que para 
comunicar con los otros hace falta verlos como son, y, para ello, debemos vernos primero a nosotros mismos. Decía San Agustín que, para hacer felices a los demás, debemos serlo primero nosotros. Para comunicar con los otros, primero debemos conocernos a nosotros mismos, como ya indicaban los viejos sabios griegos.

La ilusión, el entusiasmo, el control de los sentidos, su exploración misma, el buscar climas adecuados de conexión y de convivencia, etc., son cimientos señeros de una comunicación válida y sagaz. Hay muchos intangibles que están ahí, y que debemos tener presentes, fundamentalmente porque actúan, porque tienen una influencia suprema. La verdad es que necesitamos muchas reflexiones sobre algo tan básico en el ser humano. Seguiremos comunicando.

\subsection{Falta comunicación}

Estas reflexiones son frutos del desasosiego que genera una pérdida humana. Seguro que, con su lectura, podemos gestar la suficiente empatía para tratar bien a las víctimas, en este caso, de cualquier accidente de tráfico, sobre todo cuando sean mortales.

Es de madrugada. Alcohol, hambre no ponderada y que aparece en forma de odio, causas escritas y otras que no comprendemos, deseos realizados y otros rotos por el destino cruel... Muchos elementos se entrecruzan en una choque de vehículos monstruoso y sin sentido (todos carecen de sentido), consecuencia del sueño, del mal estado de los conductores, de la precipitación, de la falta de pericia, de la carencia de reflejos por mil motivos; y, así, los cuerpos se proyectan hacia la muerte. Ésta, la Parca, trocea lo físico, al tiempo que lo psíquico, y muere un joven de 22 años, y con él todos morimos un poco, pues este tipo de situaciones, de actuaciones desgraciadas, son un fracaso de todos, de la sociedad al completo.

$\mathrm{Y}$, con este evento, la muerte nos hace prisioneros de la incomprensión, de la falta de tiempo para comunicarnos y para conocer qué fue de aquel niño bueno que miraba con ingenuidad. ¿Qué ocurrió para que se perdiera en el laberinto de las condiciones y circunstancias que decían el filósofo y el poeta? Quizá no desapareció: puede que su inocencia quedara enterrada sin que fuéramos capaces (ni él, ni nosotros) de obtener lo racional para que no imperara todo aquello que no lo es.

Muchas dudas, demasiadas incógnitas, se desarrollan en torno a un suceso luctuoso en el que se demuestra, por "desfortuna", esa máxima que nos repetía, y repite, que "el hombre es un lobo para el hombre". Algo falló: se habla de un error humano. Quizá bebió demasiado, quizá le faltaban horas de sueño, puede que no ponderara la velocidad o el estado del pavimento... Todo pudo ser, con fallo humano incluido, claro. Cuando algo ocurre así, nos damos cuenta de que no hemos abandonado tanto como pensamos esas etapas de comienzos de la Humanidad, donde actitudes de los Cromañones se parecen más a las de los animales. 
Sin embargo, aún hoy en día hay una aceptación de la violencia como baluarte inevitable, $y$, a menudo, aunque no sea éste el caso que explicamos, como algo aceptable para imponer una supuesta realidad desfigurada. En esta situación hablamos de la violencia en la conducción, de no respetar las normas, que las violentamos, de la no aceptación de unos límites, que los rompemos, y, luego, ellos hacen lo propio con nosotros.

Lo cierto es que la tristeza, el dolor, el pesar, la soledad, la rabia contenida, la preocupación, las ausencias, se adueñan de nuestros corazones con más recurrencia de la debida, y, de esta guisa, nos acostumbramos a soportar y a asumir el riesgo de vivir más allá de las contingencias naturales, con las posturas más innobles de unos seres que no pueden ser tildados de humanos con estos comportamientos de agresiones a lo más importante que tenemos, la propia existencia.

Lo malo es que narramos mucho, que hablamos más, que opinamos, que nos contamos sucesos, que nos provocamos con fallos y con lecturas de instrumentos variopintos, pero no terminamos de evitar esas pugnas que aniquilan los espíritus y todo cuanto podríamos realizar. Como se dice en la película "Sin Perdón", "cuando se mata a alguien se le quita toda la posibilidad de ser aquello que podría haber vivido", esto es, rompemos el presente, y también el futuro, y nos quedamos sin ilusiones, sin perspectivas, fuera de juego, sin nada. Pierde el que se va, el que desaparece, pero perdemos más los que permanecemos, que, como dijo Goya, "quedamos muy solos" de cara a nuestro destino, escrito con sangre.

Un nuevo fracaso se ha registrado, por lo tanto, estos días, cuando un hombre al volante ha segado la vida de un joven que tenía todo por delante: una novia con la que casarse, unos hijos que disfrutar, una profesión que ejercer, una familia queamar, todo un universo de conocimientos que adquirir y que compartir, millones de experiencias y de alegrías por saborear, así como plenitud de momentos duros y de otros joviales: mucho que vivir, en definitiva... Y todo, todo ello, se ha quedado en el silencio de una madrugada cargada de muchas incomunicaciones previas, que, cuando menos, las podemos detectar por los resultados. ¿Qué nos pasa? Falta comunicación.

\subsection{Más que decir hacer}

No enseñamos con lo que decimos. Mostramos lo que nos gusta, lo que somos capaces de realizar, aquello en lo que creemos, con nuestros propios actos. Ahí nos definimos. Por eso es tan importante que seamos coherentes y que se complementen nuestras acciones con aquello que referimos.

Estamos en la cultura del riesgo. Hay mucha prisa, poca meditación, y conquistas rápidas, que, a menudo, hacen que se sostengan los logros sobre redes débiles. Así lo 
dicen antropólogos de la talla de Santiago Fernández-Ardanaz.

Esto supone que asumimos un coste social para aprovechar las ventajas del progreso. Lo que ocurre es que, en la mayoría de las ocasiones, ese coste social es muy alto, demasiado: las víctimas de accidentes, las soledades, los miedos, los pesares, las fragmentaciones internas y externas, a veces incluso generando dobles y triples victimizaciones, son resultados demasiado duros como para aceptarlos como un peaje obligado e insoslayable por los logros de las últimas décadas.

El caso de los accidentes de tráfico es paradigmático en este sentido. Todos los años fallecen en las carreteras de nuestro país varios centenares de personas, y son miles las que quedan "tocadas" para toda la vida. Ellas y sus familiares. Es un drama tremendo. Son situaciones que añaden complejidad a una vida que, cuando todo va bien, nos pasa desapercibida, incluso en los pequeños gestos, en lo cotidiano, en lo que nos puede suponer el hecho de tomar un trayecto $\mathrm{u}$ otro. Los detalles, la intrahistoria, se nos escapan con demasiados avisos que no atendemos, quizá por la falta de concienciación, o porque preferimos la supuesta felicidad que viene de la dejadez y de la negligencia.

Por eso es tan importante el educarnos y el formarnos en la responsabilidad, en el respeto, en el propio y en el ajeno, en lo que concierne a nuestras vidas y a las de los demás. El daño o el bien que podemos llevar a cabo con nuestros actos es tan elevado, y hasta costoso, que no debemos desdeñar la necesidad de impregnarnos de los grandes valores, de esos universales que llamamos amor, solidaridad, cooperación, belleza, igualdad, fraternidad, consideración del otro, etc. Lo espiritual debería ser más fuerte, puesto que es lo que nos salva en determinadas situaciones desgarradoras.

El aprendizaje implica acompañamiento, y los que mejor nos pueden llevar de la mano para educarnos en el respeto y el compañerismo son, precisamente, nuestros padres. La unión de intereses es la máxima de cualquier sociedad, que ha de ver en la difusión de las situaciones de convivencia el mejor afán. Busquemos el tramo de valores que nos ahorran coyunturas, o estructuras también, estériles, y que nos ubican en un aprendizaje sanador y edificante. Como padres debemos expresar y comunicar lo mejor de nosotros mismos, y no únicamente con palabras. Persigamos también la coherencia y la coordinación complementaria entre hechos y pareceres. Tengamos tino y no tentemos la suerte. Consideremos que lo que realizamos y lo que no llevamos a efecto tienen su repercusión en la actualidad y en la eternidad, como se dice en "Gladiator".

La comunicación es su contexto, sus circunstancias. Explicar las cosas dando criterios, motivaciones, versiones comprometidas desde y con la sociedad, es un baluarte que nos da garantías de futuro, y en ese campo tenemos que seguir laborando. 
Apliquemos los baremos con mesura, con insistente recorrido, esperando que todo vaya al ritmo que nos permita que seamos mayoría para formar parte de los hechos, de las opiniones y de las soluciones a los perjuicios que se puedan producir. Si es posible, que lo es, intentemos prevenirlos. En el caso que nos ocupa, los accidentes de tráfico, el 90 por ciento son sanamente evitables.

Así, cuando vayamos por la carretera, como peatones, como conductores, como espectadores de esas relaciones que son el tráfico en sus inmensas y, en ocasiones, peligrosas vicisitudes, tengamos como premisa la calma, y traslademos esa quietud y tranquilidad desde el ejemplo edificante, sobre todo si somos padres. Más, si lo somos. Cuidemos todos nuestros actos. Son las referencias para los demás. Recordemos que somos lo que hacemos. En la comunicación nos vale, sólo nos vale, la coherencia.

\subsection{Sentirnos víctimas depende de nosotros}

Se habla, hoy en día, de sistematizar las víctimas del tráfico que se producen y también de catalogar aquellas otras que se desarrollan como consecuencia de la labor más o menos meditada de los medios de comunicación de masas cuando informan sobre estos duros acontecimientos. Ésa es una tarea pendiente, difícil de realizar, y con seguridad sin unos límites convenientemente marcados, habida cuenta de que irán surgiendo, si nos ponemos manos a la obra, más denominaciones y conceptualizaciones de las que pensamos. Hablamos de personas y de circunstancias, y eso genera muchas dudas de apreciación. De lo que se trata, o debería, es de no gestar equívocos y errores.

La vida es lo que nosotros hacemos de ella, en función de lo que determinen las condiciones que tengamos en cada momento. A menudo hay etapas cruciales, pocas, que caracterizan a las demás, esto es, a la mayoría de los días, meses y años que experimentamos. Ortega y Gasset decía que somos nosotros y nuestras circunstancias, aludiendo a lo mismo que estamos diciendo aquí. Por eso, porque hay un yo en la reflexión del afamado filósofo, es precisamente en este punto donde debemos y queremos hallar "la primera posibilidad de víctima", incluso para superar, y, mucho mejor, para evitar accidentes de tráfico.

El que nos sintamos más o menos culpables, el que seamos más o menos felices, el que tengamos más o menos moral, el que seamos más o menos bondadosos y fieles a nuestras convicciones, el que toleremos, el que busquemos la belleza, el que disfrutemos con lo poco, el que tengamos mesura y comprensión hacia los otros, el que nos conformemos con lo que poseemos con la suficiente gratitud... el que seamos dichosos con lo que somos, en definitiva, influye en nuestra forma de vivir y de ser, en nuestras actitudes. 
La primera víctima en nuestras vivencias somos nosotros, si no somos capaces de ver con ojos plenos de hermosura, de comprensión, de compasión y en busca de alicientes sin más compromisos que esforzarnos para que las cosas vayan a mejor hasta donde sea posible. El intentarlo es ya un éxito. Lo que ocurre es que no siempre ponemos ese empeño. Cuando nos ocurra una tragedia (un accidente de tráfico, por ejemplo), esta actitud se ha de potenciar sobremanera. La ilusión y el optimismo contribuyen a superar cualquier fiasco.

Por eso, la recomendación es amarnos primero a nosotros mismos, como diría San Agustín, y a partir de ahí brotará el amor hacia la Naturaleza y hacia toda la Creación. Ya se sabe que es más fácil perdonar, creer, comprender, sentir, ver en positivo, etc., si amamos a los protagonistas de las acciones que tenemos que catalogar, siempre brindando como origen la estima interna y a nuestro propio ego como punto de fermento ante los diversos eventos controvertidos y contradictorios que nos puedan ocurrir. Lo importante es superar los avatares. Hay que tenerlo presente en el caso de los accidentes de circulación. Avanzar tras lo negativo.

En este mundo de prisas, de competencias, de aceleraciones, donde el corto plazo es el rey, la primera víctima de lo que hacemos, de lo que omitimos, de aquello que es perjudicial, incluso de los triunfos, somos nosotros, pues pagamos un alto coste en perspectiva, en ánimo, y en visión de presente y de futuro. Por desgracia, a menudo el tiempo se pierde en cosas nimias, $\mathrm{y}$, por ende, no siempre vemos lo importante.

Además, consentimos recurrentemente en aplicar períodos de estudio a cuestiones que no nos sirven para avanzar, si acaso para gestar más enfrentamientos y frustraciones. Seamos la medida de la superación de los malos episodios, y así se ha de ver cuando tengamos un accidente $\mathrm{y}$, sobre todo, cuando informemos de él. Conectar con las víctimas en el mejor sentido será vital para mostrarlas en toda su dignidad.

Ante los fracasos o incidentes reales o ficticios que nos rodean, lo primero que debemos defender es el equilibrio mental propio y de nuestro entorno, para que seamos capaces de enderezar el rumbo de aquellos eventos que no salen como queremos, o como pensamos que deberían suceder, amén de la serie de acontecimientos accidentales que se producen sin que les tengamos que dar más significación que el interiorizar que la vida es así, y, pese a todo, nos debemos insistir que hay que seguir, porque así debe ser. No podemos caer ni dejar caer, a las primeras de cambio, a nuestras almas, pues, si así sucede, detrás irán nuestros cuerpos. Esta actitud de la víctima, que aconsejamos, también ha de ser una postura coherente para el informador, para el periodista.

La primera fortaleza, consecuentemente, ha de ser interna. Hagamos acopio de energías para capear los períodos de crisis (inevitables, por otro lado), y para saborear el día a día con sus peaueñas v grandes onciones. aue las hav. Cuando 


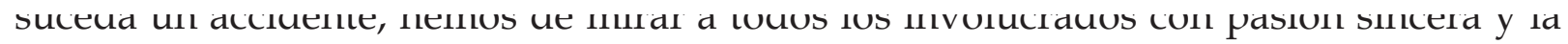
suficiente salubridad. Saquemos provecho a lo cotidiano y evitemos ser víctimas innecesarias de nuestro propio afán o de la carencia de carácter.

Las cosas pasan, y lo importante es no hacer un daño posterior y añadido. De ahí que sea necesaria una buena perspectiva, una mejor formación y una extraordinaria deontología. Por lo tanto, cuidemos las formas y los elementos internos, pues esa víctima interior que podemos llevar dentro es la más peligrosa, fundamentalmente por difícil de detectar.

Cuando se dé un accidente, no ocasionemos más dolor, ni más frustración, ni problemas físicos o mentales superpuestos a la realidad sangrante en sí. Vayamos, por favor, con buenos ejemplos hacia adelante.

\subsection{No multipliquemos la "victimización"}

Las nuevas rutinas diarias, los comportamientos en los diversos ámbitos de nuestras vidas, así como el uso de las tecnologías llamadas nuevas y que no lo son tanto, puesto que ya se vienen utilizando desde hace tres décadas, nos llevan a situaciones que estrenan delitos y, por ende, que inauguran denominaciones de nuevo cuño en el campo de la "victimología". Incluso se dan acontecimientos que habría que catalogar previamente en la fase que correspondería a los expertos en criminología.

Nos referimos a los delitos de acoso, de humillación, de persecución, de intromisión en la tranquilidad y en la intimidad de las personas, así como a la violación de sus circunstancias, cuando las víctimas de un accidente, cualesquiera fueran sus consecuencias, se ven en un entramado de redes informáticas, de blogs, de portales, de correos electrónicos, de resúmenes de noticias, etc., donde aparecen fotos que dañan la vista y la conducta humana en torno a un evento accidental que deteriora, paralelamente, con todas las claves, dosis, estadios e interpretaciones posibles, la imagen y las señas de identidad de una o de varias personas. Las malvadas intenciones son las que hemos padecido durante siglos, pero su puesta en escena, su modo de operar en la actualidad, es otro.

Las nuevas tecnologías han inventado nuevos delitos: el acoso múltiple y multiplicador, por abundancia innecesaria, con noticias nefastas sobre el tráfico y sus resultados a través de Internet, en muchas ocasiones con identidades falsas, ha proliferado, y siembra la inquietud de cientos de personas que reciben informaciones, consideraciones, pareceres y sugerencias sin que sea fácil poder actuar contra el agresor o los agresores precisamente por la impunidad que supone la distancia física, geográfica, social, cultural y hasta intelectual. Un delito de este calibre se puede cometer a miles de kilómetros, utilizando unas redes entrelazadas que no son sencillas de detectar.

El supuesto atractivo de este tipo de noticias proviene del morbo inherente a las 
imágenes mostradas, del amarillismo de las historias que se cuentan, de los escenarios brutales que se destacan. Es el horror de ver a las víctimas en unos primeros planos que escandalizan, y en esa pretensión de atemorizar o de generar adrenalina se sustenta su empuje y su consumo, que suele registrar cifras vergonzantes.

La ley, como suele suceder, va por detrás de las situaciones que establecen la modernidad y sus tecnologías informativas e informáticas. Por eso es preciso que estemos atentos a las vicisitudes que nos podamos encontrar. Ser víctima, o tener cerca a una víctima, es más fácil de lo que pensamos.

De lo que se trata es de tomar medidas preventivas cuando percibamos imágenes de alguien a través de los portales que podamos consultar; y hemos de ayudar, igualmente, a aquellas personas de nuestro entorno que se puedan ver en problemas de esta índole, esto es, que aparezcan en un accidente, con heridas, ensangrentadas, en actitudes dolientes...

El acoso mediático, con fórmulas ruidosas de programas, con víctimas por doquier, forma parte de nuestro panorama actual. No conoce, este delito (cuando no informamos bien de las víctimas), ni consideraciones sociales, ni sexos, ni edades, ni culturas o formaciones. Afecta a todas las capas, en todas las coyunturas y estructuras posibles. Precisamente por esta razón debemos estar preparados para actuar y no ser pasivos ante posturas y actividades que sean perniciosas.

La mutilación de la dignidad humana con todas sus letras se fundamenta en generar vacíos y distancias, en intentar estructurar situaciones de dominio, de obligarnos a que veamos perjuicios y daños físicos y materiales imponiendo una estética de brutalidad donde lo humano no prevalece, al menos no lo mejor.

No dejemos que proliferen estos actos, que nunca sabemos cómo empiezan y menos aun cómo terminan. Sabemos que fomentan el dolor. Dañan, asimismo, a las personas, y, no lo olvidemos, rompen a toda la sociedad, que no ha de ser tolerante, en este sentido, en lo más mínimo.

\subsection{Reflexiones ante los avatares de la circulación vial}

Aglutinar los intereses informativos, los las empresas periodísticas, los de los profesionales de la comunicación, los de la ciudadanía, y los de las víctimas de los accidentes de tráfico, amén de otras consideraciones, no es un asunto fácil, sobre todo porque, en los vértices de las actividades de cada colectivo, hay un fin que, con independencia de que sea principal o accesorio, se superpone, o lo intenta, a los objetivos de los demás. Hay demasiados intereses en juego, a menudo financieros, que son los más complicados de soslayar.

En todo caso, en este trabajo vamos a defender lo obvio, es decir, la dignidad de las personas. su honor. su intimidad. su derecho a un recogimiento. a un luto.a a 


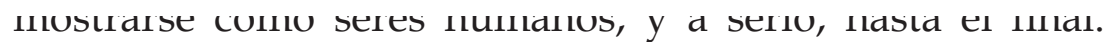

Por ello, todo lo que se cuente, cuando esté bajo investigación (como se suele decir "sub iudice"), ha de presentarse con cautela, con presunciones de hechos y de inocencias de los mismos. Es más: cuando algunos hechos no sean demostrables, hemos de omitirlos, salvo que los contextualicemos bien y nos sean precisos para el relato o historia, eso sí, siempre evitando hacer el mal a alguno de los protagonistas.

Ponderar derechos es crucial. Por supuesto, no podemos inferir ni deducir porque sí, ni podemos fomentar explicaciones, ni mucho menos direccionar el sentido de la marcha de las investigaciones o sus resultados. Por eso, tengamos especial cuidado con las preguntas, con sus sesgos, y tengamos en cuenta los condicionantes que ponemos, o podemos poner, en las respuestas a raíz de los cuestionamientos que formulamos y de los resúmenes que desarrollamos. A veces ocurre que deterioramos la realidad. Una contestación a medias puede ser dañina, y eso puede ocasionar una mayor victimización o incluso otras víctimas.

Las fuentes, en éste y en otros casos, son cruciales para dar una noticia de manera oportuna. Hay que fomentarlas, valorarlas, usarlas, cuidarlas, respetarlas... Evitemos, asimismo, el sensacionalismo, la truculencia, ese amarillismo morboso y mordaz que supera las sospechas, los rumores, y hasta los mismos indicios, en busca de resultados oportunistas. No hagamos un tipo de periodismo que practique la tierra quemada. No todo vale. Los resultados negativos o en vacío pueden ocasionar un deterioro atroz.

Cuidado también con los elementos verbales. No todas las palabras significan lo mismo. Ponderemos también los potentes adjetivos o adverbios, que pueden distorsionar los resultados. Pongamos lo necesario, lo que informa de veras, y no tanto lo que no desempeña ese papel. Por señalar un ejemplo, a menudo hablamos de nacionalidades cuando en sí no aportan información, y sí el morbo de esos efectos estereotipados que surgen en el sentido de atribuir falta de cultura o de educación, si fuera el caso. Parece que algunas "castas" son más propicias a vivir en el desastre o el accidente, o incluso a tolerar este tipo de situaciones, cuando no es así, salvo por la injusticia temporal y espacial.

Igualmente, hemos de tener muy presentes los apoyos gráficos. Los iconos suelen ofrecer destellos que nos pueden deslumbrar. Las imágenes significan demasiado para no pensar en su verdadero valor. Procuremos no poner esos primeros planos aberrantes que sugieren emociones contrapuestas y que no aportan información pura y propiamente dicha.

Tengamos en cuenta todas las sensibilidades: primero las de los intervinientes en un 
suceso y las de sus familiares, y, por supuesto, las de los colectivos que debemos proteger especialmente, como es el caso de los menores. A menudo no pensamos que, cuando ponemos una foto de un accidente de tráfico con muertos en una primera página de un periódico, al pasar por delante de un quiosco la puede ver cualquiera. La influencia nefasta está ahí, y debemos reconocer que es de esta guisa para tomar algún tipo de medida siempre desde la autorregulación.

El equilibrio informativo y el respeto, además del conocimiento de lo acaecido, es garantía de una buena noticia, de un buen planteamiento, que, asimismo, ha de tener una buena arquitectura, una óptima técnica, un léxico rico y una conceptualización atrayente. Cuando tratamos informaciones que tienen que ver con la sensibilidad, todo esto lo hemos de exponer y aplicar al máximo.

Los daños que se pueden derivar de malas prácticas, de malas interpretaciones, de ligerezas, de inseguridades, de consentimientos, de negligencias, de limitaciones en el saber, de vaguedades, etc., son difíciles de cuantificar. Por ello, los debemos evitar especialmente.

\subsection{Contemplaciones globales de lo que nos ocurre}

Pensemos. Vamos por la carretera, y no siempre advertimos el paisanaje, que decían los escritores de 1898, esto es, lo que ocurre anónimamente, a veces de manera insignificante, con compromisos variados, que no contemplamos en todo momento en las opciones que nos pueden brindar.

Tendríamos que ir disfrutando, con atención en la carretera, pero oteando lo que ocurre, lo que hacen otros conductores, lo que nos envuelve, lo que nos puede transmitir algo en el curso de la conducción. No se trata de fijarnos en todo, sino de empaparnos del entorno, del envoltorio del viaje, y para eso no podemos ir tan deprisa como a veces nos dicen las estadísticas, que se convierten en hechos inapelables. Una velocidad moderada puede ser el reflejo de nuestro espíritu y un buen espejo en el que mirarnos para dar con solvencias y soluciones más o menos variopintas.

Respetar la norma (todas las normas) no es sólo una virtud de convivencia: es una necesidad para vivir, para sobrevivir, nosotros, y los demás. Hemos de señalarlo, de protagonizarlo, de realizarlo, que es como convencemos a los otros de lo que reseñamos diariamente. Los hechos son las auténticas razones.

Gozar de la vida es reconocer que hay límites, y eso supone respeto y otros universales como son la solidaridad, la bondad, el amor, el buen deseo, la cooperación, la comprensión, la tolerancia, etc., como base para una convivencia pacífica y justa, dos elementos que cabalgan al unísono, o que deben. Es difícil que se dé el uno sin el otro. La paz es la consecuencia de la justicia, y ésta aparece cuando hay paz. Por ende, fomentar situaciones de equidad y de correspondencia es el sisstento de 11n norvenir estrinendo. 
En materia de seguridad vial hemos de incrementar las buenas experiencias y alejarnos de las malas, que seguramente habría que contar menos en los medios de comunicación masiva. Sería una buena praxis poner los modelos positivos y olvidarnos de los negativos, o, como mucho, tenerlos en cuenta para no volverlos a repetir.

Además, hemos de buscar empáticamente qué es lo que nos sucede, con valor, poniendo buenos ejemplos y paradigmas, siendo nosotros mismos, adecuando los contextos, que son los que dan avances, si es posible desde la mesura, a la comunicación misma. Hagamos caso a nuestro interior procurando que las cosas funcionen.

Cuando veamos informaciones sobre seguridad vial que generen desasosiego y más y más intranquilidad, de una manera constante y repetida, es que no vamos por el buen camino. El hecho es que las vemos con demasiada permisividad y recurrencia.

Así, hemos de procurar fomentar la alegría frente a la pena, el dolor o la tristeza. Hagamos caso a nuestro interior sin complejos, en la necesidad, que también ha de ser un compromiso obligado, de reconocer que todos somos iguales, porque lo somos, porque tenemos los mismos derechos, y eso supone igualdad de opciones, de oportunidades. La cultura en materia de conducción y de convivencia vial ha de ser exponente de un buen hacer societario, y por ahí convendría laborar.

Por lo tanto, la cultura del riesgo, que algunos antropólogos ven como algo inevitable, hay que sustituirla por la cultura de la convivencia, y por eso no cabe que nos veamos en diferentes campos de batalla a la hora de afrontar la cohabitación vial. No hay más que una tierra, y ahí entramos, debemos, todos, desde la consideración de que los derechos no pueden aparecer eternamente en contradicción.

La cooperación es sosiego, concordia y pacto entre todos para que el modelo funcione desde la cesión de cada cual en lo individual y, a veces, también en lo colectivo. No podemos consentir, como un hecho imposible de evitar, las víctimas en las carreteras y la proliferación de coches más y más potentes con conductas en la conducción cada vez más duras. El resultado es el que es, aunque a veces se maquillen las cifras.

No tenemos que asumir, por las buenas, desde la impotencia, que todos los años debe haber miles de muertos en las carreteras por fallos humanos y mecánicos. Sabemos que la mayoría de esos fallecidos son evitables. Hagamos todo lo posible para que sea así, como miembros de una ciudadanía responsable y, asimismo, anhelando otro papel de los medios de comunicación, que, en el caso de las víctimas que nos ocupan, han de ser más prudentes, racionales y coherentes. Hay que construir y no destruir. El morbo es un mal acompañante, y el desconocimiento de lo que hablamos también. Aunque no sean fruto de la norma, aparecen el uno y el otro. 
En consecuencia, hemos de concebirnos todos como aliados: las empresas periodísticas, los profesionales y los consumidores de la información. No puede haber una sumisión total a las grandes audiencias a través del fomento del amarillismo. Si no optamos por cambios consensuados entre todos, será la pescadilla que se muerde la cola. Hay que girar ese sentido de la marcha y llegar todos juntos a la meta. Tenemos mucho en juego para que no lo meditemos así.

\subsection{Buenos usos en los procesos comunicativos}

No es sencillo reconocer en ninguna sociedad que lo que sucede en ella es parte de todo el panorama que vamos construyendo de uno $u$ otro modo entre aquello que realizamos y lo que dejamos a un margen.

Las guerras que retratan los informativos, los asesinatos, los robos, las controversias, las violencias de género, las imágenes impactantes y demoledoras con las que convivimos cada día, nos hacen aceptar ese modelo imperante en el que parece que los accidentes de tráfico, por poner un ejemplo, son inevitables a la condición humana, cuando, ciertamente, son consecuencia de una mala educación vial, de la carencia, en muchas ocasiones, de óptimos hábitos de convivencia. Pidamos, en éste y en otros supuestos, mucho respeto.

Los sesgos con los que presentamos las informaciones son muchas veces precipitados, a menudo sin contrastar lo suficiente, buscando atractivos por encima de criterios más racionales, con planteamientos de sentimientos en estado profundo o superficial, y siempre en pos de una audiencia que, pese a todo, se halla muy fragmentada por la "multi-oferta" televisiva.

Además, todos competimos por los mismos espacios, de la misma manera, con idénticas perspectivas, con ópticas que se estiran desde márgenes estridentes. Eso, exactamente, no contribuye a construir sociedad. Saturamos, y buscamos perchas y cebos de modos, en ocasiones, poco ortodoxos.

La realidad se basa en unos usos que tienen como base que las malas noticias son las mejores para un periodista (o, mejor dicho, para su empresa), pues venden más y más rápido el producto, sin que haya necesidad de pensar sobre lo que estamos ofreciendo a través de los medios de comunicación masiva. No invitamos a pensar, sino a devorar las imágenes con ilusión y pasión, sin ver más allá, sin observar sus ecos, sus aspectos evitables, sus posibilidades de conseguir unas mejoras ciertas.

Parece que el mundo tiene que discurrir así, y eso no es verdad, pero es la certeza que trasladamos. La superficie gana, en ciertas oportunidades mal aprovechadas, a lo denso, a lo que debería serlo.

El parte cotidiano nos recuerda que leemos en titulares los contenidos que mostramos en niezas cada vez. más cortas. v sorteamos los ohstác11los de todo 11n nroceso d11e. 


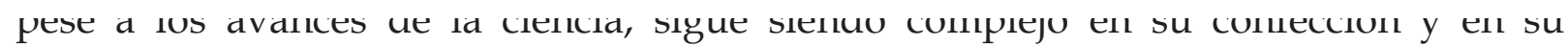
difusión. Las imágenes se nutren de sus perfiles más atractivos, de modo que las estampas que mostramos a menudo neutralizan o catalogan el mensaje muy por encima de lo que narramos en él, y no siempre ganamos con ello, claro.

El 80 por ciento de lo que comunica es imagen, y, cuando hay contradicción entre lo que contamos en el off y lo que se percibe visualmente, predominan las estampas gráficas que se suceden respecto de lo que explicamos en la noticia en cuestión. No siempre reparamos en ello, pero debería ser así. Hay influencias que no tenemos en cuenta, o sí, pero, en todo caso, ahí están.

En comunicación decimos que una cosa es lo que se quiere contar, otra cosa es lo que se cuenta, y otra, a veces diferente, lo que se entiende finalmente en ese proceso. Como las personas y sus circunstancias de recepción comunicativa son dispares, también lo son sus interpretaciones, y ello lo deberíamos tener presente.

Sí, es cierto que sabemos que esto es así, y, a menudo, nos curamos en salud, esto es, tenemos en cuenta los filtros $\mathrm{o}$ distorsiones que se pueden producir. Consecuentemente, nos vamos a lo seguro, y, como lo que se quiere desde los medios masivos es llegar a cuanta más gente mejor, se ofertan sentimientos por encima de raciocinios, que no siempre se disponen con el criterio más acertado en aras, como sabemos, de un consumo grande, que es lo que perseguimos.

El medio es el mensaje, como nos recordaba McLuhan, y ahora, con unos hábitos de consumo tan esperpénticos como hipócritas, donde no confesamos devorar determinados programas (Todo el mundo dice ver "La Dos"), nos hallamos ante una situación difícil de vislumbrar en sus formas y en sus posibles soluciones ante los agravios o ruidos que entre todos fomentamos. La coherencia, que es tan comunicativa, falta con demasiada recurrencia.

Busquemos, por ende, los modelos que nos inserten en las posibilidades en positivo. La violencia engendra violencia. Los mimetismos ante las modas o la iconografía que parece representar a la sociedad se imponen con sus aspectos más sangrantes y truculentos. No deben servir los medios de comunicación como correas de transmisión de los eventos más luctuosos, no sin un ánimo de construir la comunidad de personas a la que sirven a través de una vocación de interés público que a menudo no aparece por ninguna parte.

Han de analizar, precisamente estos medios, los motivos de toda esta fenomenología "victimal", procurando alcanzar cotas de desarrollo, de progreso y de "aminoración" de los peores compartimentos. Hemos de ser críticos con aquello que no edifica a la sociedad: no cabe siquiera que no tomemos partido y que seamos inocuos. Ante la violencia hemos de estar en el lado opuesto, fomentando el 
pacifismo, la tranquilidad, el sosiego, la idea de pacto, etc. Aquí no puede haber neutralidad.

Todos somos iguales ante la ley: lo pregona el artículo 14 de la Constitución, que añade que es así con independencia de las circunstancias o condiciones de cada cual. Es un derecho fundamental, como el derecho a vivir, como el derecho a una formación o a una sanidad integral.

Por lo tanto, los desvíos de ese derecho pleno, la no consideración, la ignorancia, la falsedad, la omisión de nuestros deberes ciudadanos en este plano, constituyen una actuación lesiva y delictiva que hemos de perseguir y de neutralizar en el grado que sea y lo antes posible. No cabe mirar para otro lado, o, como diría Bertold Brecht, cuando vengan contra nosotros, o nos perjudiquen gravemente, ya no habrá posibilidad de respuesta clara, diáfana y real.

Compartamos buenos deseos, óptimos fines, en el convencimiento de que la bondad genera sentimientos con el mismo perfil. No somos conscientes de la influencia que tienen las numerosas horas que percibimos cargadas de violencia, de amarillismo, de versiones estridentes de una sociedad llena de sombras, de apatías y de enfrentamientos. Ese tipo de dinámicas sólo generan más fluctuaciones en negativo.

Hay un efecto perverso y contaminante en las malas conductas, que influyen como modelo de convivencia, $\mathrm{o}$, mejor dicho, de carencia de base para la convivencia. Por eso, la cercanía, la empatía, los silencios, las escuchas, los procesos proactivos en comunicación, las sensaciones y los raciocinios en tradicional equilibrio, las versiones de la realidad en sus fortunas más esperanzadas y alegres, han de darnos el impulso para hablar de las mayorías que hacen menos ruido y que contribuyen a construir sociedad en todos sus aspectos determinantes. No cabe el consuelo de decirnos que las cosas suceden porque sí y que no las podemos evitar. La crisis actual tiene mucho que ver con la no defensa de los mejores valores morales y éticos, ésos que los griegos llamaban universales.

Sintamos que en el proceso comunicativo podemos cambiar las tornas para que los procedimientos "victimo-lógicos" no proliferen como si fueran armas letales que no podemos desarticular. Somos más capaces de lo que pensamos de "modificar-nos" para mejor. Somos dueños de nuestro destino, a pesar de toda la casuística que nos quieran vender los medios propagandísticos de eventos nefastos. Cojamos las riendas para nosotros y meditando acerca del bienestar común, en este caso para mejorar la presencia y las actitudes en torno a las víctimas de accidentes de tráfico.

\section{CONCLUSIONES}

Cuando informemos de accidentes de tráfico, debemos tener en cuenta la lógica y el sentido común como instrumentos vitales de trabajo. Así, lo ideal es que evitemos: 
a) -Lus pinterus pianius inuinusus.

b) -Mostrar a los menores, sea cual sea su participación o presencia en un accidente.

c) Coger totales en los primeros momentos del accidente de las víctimas y/o familiares, sobre todo si se hallan dañadas o heridas física o psicológicamente, que es, por otro lado, lo más normal.

d) La dramatización excesiva de los hechos.

e) Las elucubraciones o rumores.

f) -Las malas intenciones o apreciaciones de los que son parte del escenario del accidente.

g) -Las voces de gentes no expertas hablando como si lo fueran.

Es fundamental que no hagamos daño, y que realicemos todo lo posible para no generar más dolor.

Como complemento de lo anterior, vamos a defender siempre la situación de los más débiles, en este caso de las víctimas, de los que sufren, de los protagonistas y de sus allegados y de gentes cercanas. Por ello, procuremos:

a) Hacer noticias constructivas.

b) Consultar varias fuentes. Crucemos los datos que tengamos, y también las impresiones.

c) Ponderar derechos. Pensemos en conseguir más beneficio que perjuicio, $\mathrm{y}$, fundamentalmente, veamos, en la supuesta suma, más avances informativos que penas cuando deterioremos algún derecho. Si no hay progreso comunicativo, la praxis es mala.

d) "Aguantar" una noticia hasta que tengamos conformados todos sus datos y circunstancias.

e) Tratar con mimo y ternura a las víctimas, y, cómo no, a sus familiares y allegados. Pensemos que son personas de nuestra propia familia. Será más difícil que nos equivoquemos así.

f) Dar una visión con el mejor y más extenso criterio.

g) No hacer preponderar primeros planos sobre lo que queremos contar. El relato es importante. Reequilibremos impresiones, razones y derechos.

h) No mostrar mutilaciones, ni sangre, ni cuerpos en estado de enorme desgaste, deterioro o cuerpos de fallecidos. No aportan, sobre todo cuando son planos cercanos, nada sustancial a la información. Lo mejor es practicar la distancia en las imágenes cuando éstas, como es el caso de los accidentes mortales, son duras. La mesura ha de ser el eje de sustento de las informaciones con víctimas y sobre ellas. 
La idea principal es defender la DIGNIDAD de las personas con Respeto, Consideración, Bondad, Mesura, Equilibrio y desde el Amor que debemos profesar a quienes son conciudadanos nuestros, con una apuesta de entrega mucho mayor al hecho de vivir a la hora de contar una desgracia de semejante calibre (aquí nos referimos a los accidentes de circulación).

\section{Juan Tomás Frutos}

Licenciado y Doctor en Comunicación por la Universidad Complutense de Madrid. Doctor en Pedagogía por la Universidad de Murcia. Está en posesión de seis másteres: Producción en Radio; y Producción en Televisión; Publicidad y Comunicación; Pedagogía; Literatura, y Antropología. Profesor de la Universidad de Murcia. Profesor colaborador de varias Universidades extranjeras en Bolivia y México. Dirige el grupo de Investigación Universitario "La víctima en los medios". Trabaja en RTVE desde el año 1989. Actualmente, es Editor de Informativos en el Centro Territorial de TVE en Murcia. Decano del Colegio de Periodistas de la Región de Murcia, y Presidente de la Asociación de la Prensa de Murcia desde el año 2007. 